\title{
Aggregate QTCL Interval
}

National Cancer Institute

\section{Source}

National Cancer Institute. Aggregate QTCL Interval. NCI Thesaurus. Code C123448.

The correction of the aggregate of QT intervals using a linear correction formula, which allows for the comparison of QT intervals across a range of heart rates. 